\title{
PENGENDALIAN MODUL ROTARY HANDLING STATION BEBASIS SEQUENTIAL FUNCTION CHART (SFC)
}

\author{
Deli Budiantoro'), Agus Halim²) dan Soeharsono ${ }^{3)}$ \\ ${ }^{1)}$ Program Studi Teknik Mesin, Fakultas Teknik Universitas Tarumanagara \\ ${ }^{2)}$ Praktisi PT. Matahari Megah \\ 3) Jurusan Teknik Mesin Universitas Trisakti \\ e-mail: delibudiantoro@gmail.com, a9ushalim@gmail.com,gatotsoeharsono@yahoo.com
}

\begin{abstract}
The system used in this day and age has made progress in its operations. In industry itself many use automated systems that only require a small operator to run a tool because it saves time, and safety is guaranteed. In this time the tool discussed Handling Station Rotary pneumatic system uses motion to move this tool. So that the tool can be moved according to plan also required the "brains" to run this tool. Where the brain is a Program Logic Controller (PLC) to save a program that has been created in order to move the tool. Program created in this thesis using Sequential Function Chart (SFC) using Zelio Soft application. For components that are needed in this form of censorship tool as a reader, selonoid as air regulator to move from such a device.
\end{abstract}

Keywords: Automation, rotary handling station, pneumatic, PLC, SFC, zelio soft, sensors, selonoid.

\section{PENDAHULUAN}

Perkembangan industri saat ini banyak membutuhkan sistem otomasi, yang merupakan suatu teknologi yang digunakan untuk melaksanakan proses atau prosedur kerja tanpa bantuan manusia. Pekerjaan ini dilakukan dengan menggunakan program instruksi yang dikombinasi dengan suatu sistem pengendali untuk menjalankan instruksi-instruksi tersebut [1].

Untuk mengendalikan pergerakan dan sistem simulasi mesin tersebut, maka dibutuhkan piranti atau peralatan untuk mengatur semua itu. Salah satu piranti yang digunakan secara luas untuk berbagai keperluan pengendali proses adalah Programmable Logic Controller (PLC) yang digunakan sebagai kontroler yang murah, fleksibel dan mudah sehingga menghasilkan pengembangan yang dapat digunakan dengan cepat dan dalam berbagai macam aplikasi industri [2]. Basis sistem pemrograman yang sering digunakan pada PLC adalah sistem Ladder dan sistem Function Block Diagram (FBD). Ladder Diagram terdiri dari simbol grafis mewakili ekspresi logika, kontak, koil, dan output yang dikombinasikan[3].

Bahasa pemprogaman yang digunakan untuk program PLC yang dalam istilahnya adalah blok grafis. Yang digambarkan sebagai sebuah bahasa grafis untuk menggambarkan sinyal yang masuk melalui suatu fungsi blok.

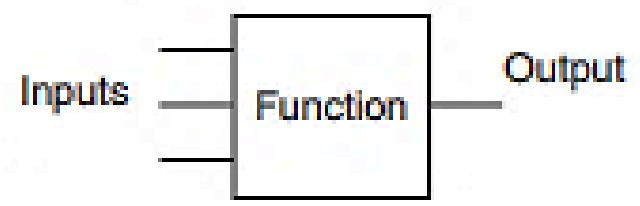

Gambar 1. Function block diagram [4].

Keterangan gambar:

Input $\rightarrow$ Function $\rightarrow$ Output

Sebelum sinyal input yang berasal dari sensor, switch, tombol masuk ke Central Processing Unit (CPU), sinyal melewati modul input. Sedangkan setelah sinyal diproses di dalam CPU, maka sebelum menggerakan aktuator, sinyal output masuk melewati modul yang ada. Dari modul input dan output kita dapat menentukan jenis suatu PLC dari hubungan antara CPU dengan modul input, yaitu compact PLC dan modular PLC. Compact PLC adalah bila modul input, CPU dan modul output dikemas dalam suatu wadah. Modular PLC adalah bila modul input, modul output dan CPU dikemas terpisah[5]. 
Dalam penelitian ini, dijelaskan mengenai pembuatan sistem pengendalian dimesin otomasi bersistem modular untuk mensimulasikan mesin yang ada di industri dalam skala laboratorium.

\section{METODE PENELITIAN}

Dalam penelitian ini pengendalian modul rotary handling station, metode yang digunakan adalah studi literatur, dan pemrograman dengan menggunakan Zelio Soft 2 V4.5.

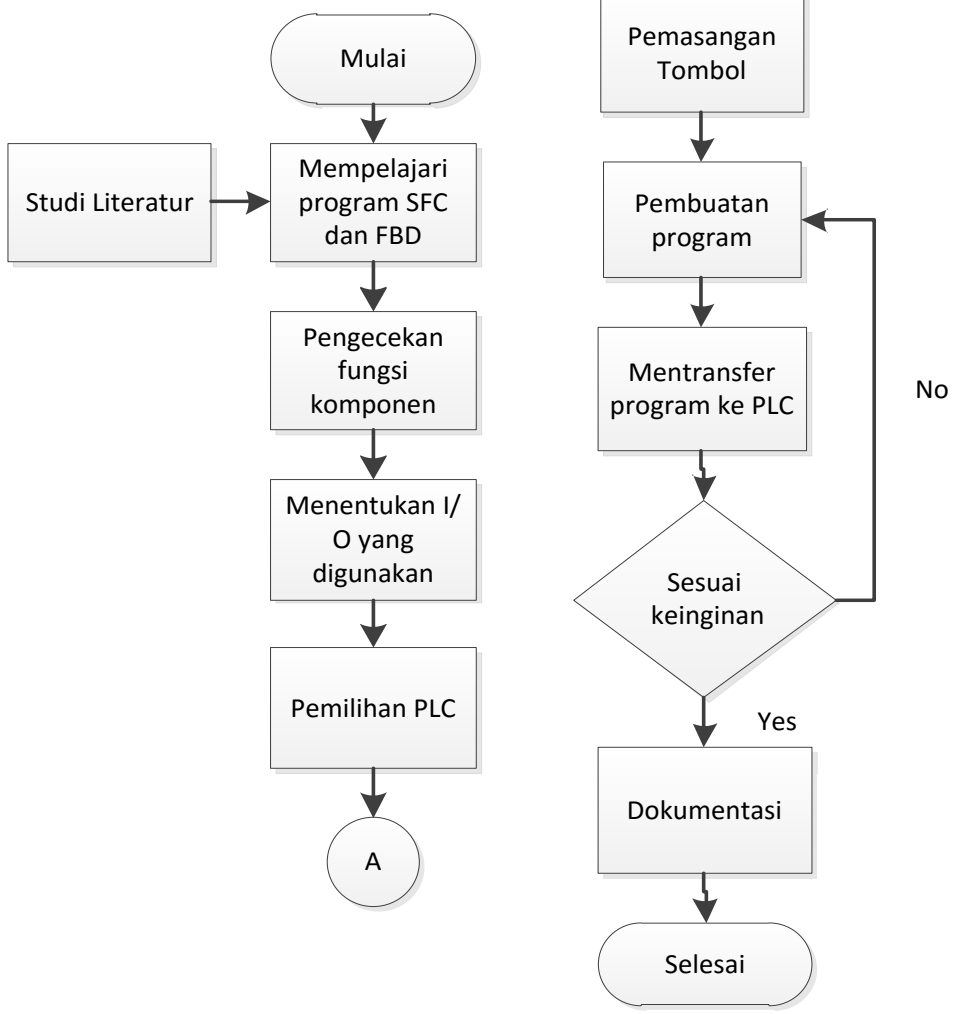

Gambar 2. Diagram alir penelitian

\section{Komponen-komponen modul rotary handling station}

Di dalam fungsinya terdapat komponen yang digunakan pada modul rotary handling dapat dibagi menjadi 3 bagian, yaitu:

1. Rotary Actuator

2. Gripper

3. Cylinder Lifting

Contoh gambar pergerakan modul rotary handling dapat dilihat pada Gambar 4.

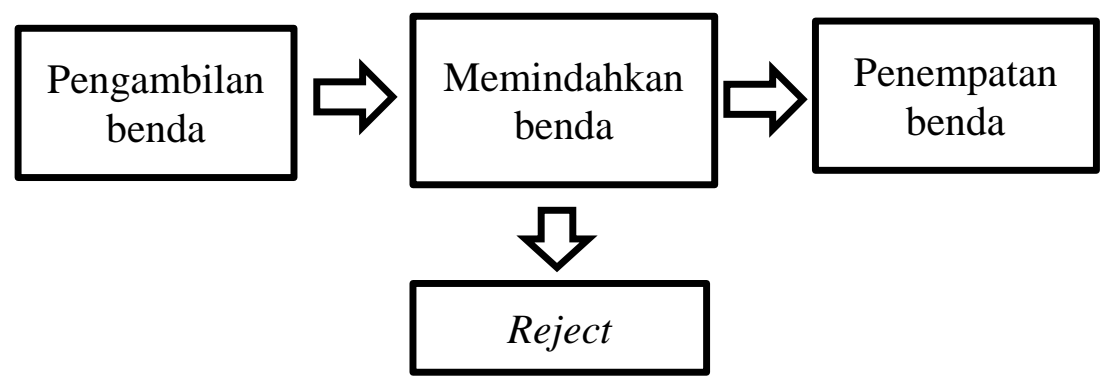

Gambar 3. Aliran pergerakan modul 


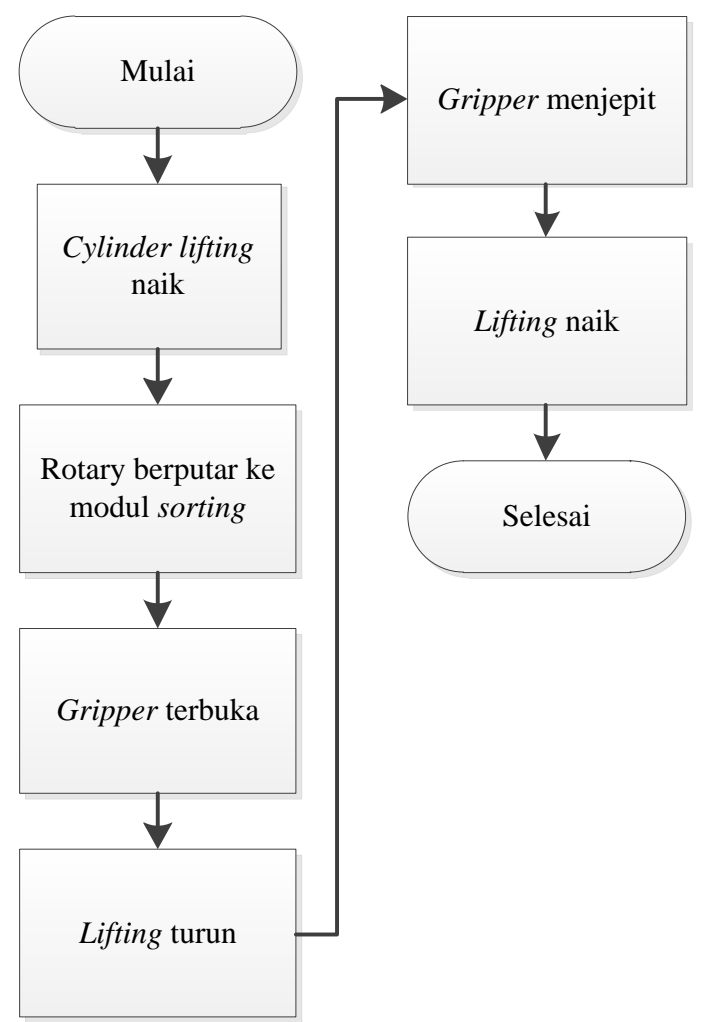

(a)

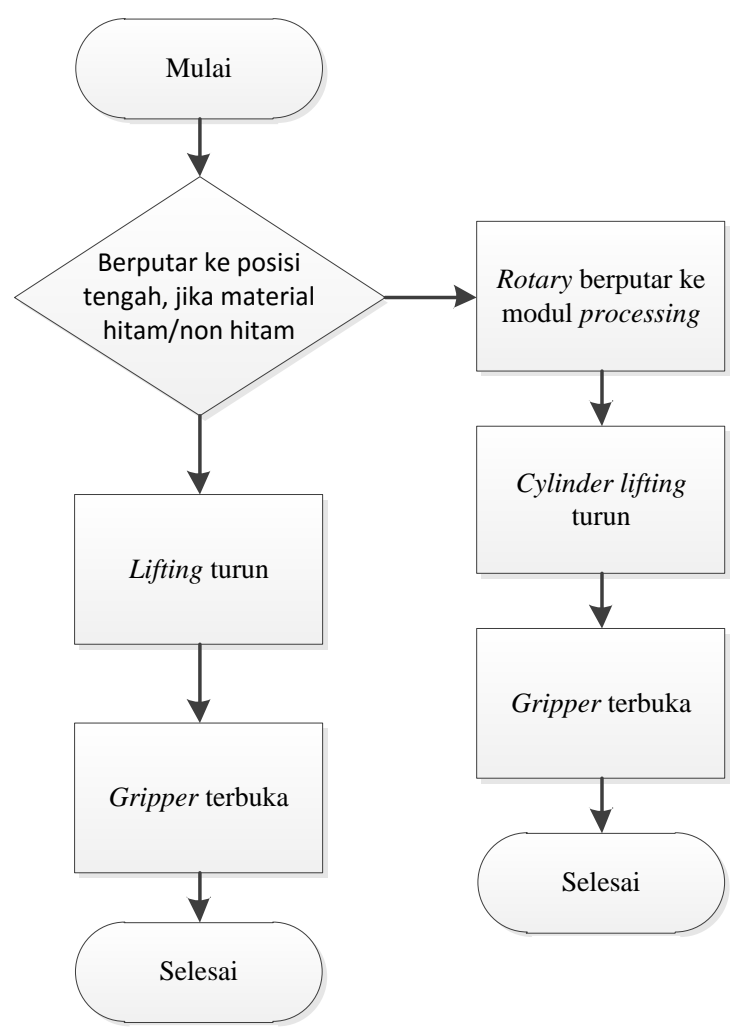

(b)

Gambar 4. (a) Digram alir proses pengambilan material, (b) diagram alir proses memindahkan, reject, dan penempatan material

\section{HASIL DAN PEMBAHASAN}

\section{1) Pengujian Benda Hitam}

Untuk mengetahui kinerja dari proses modul rotary handling ini, dilakukan pengujian pertama terhadap modul alat ini, dengan menguji proses pergerakan modul alat terhadap benda berwarna hitam.

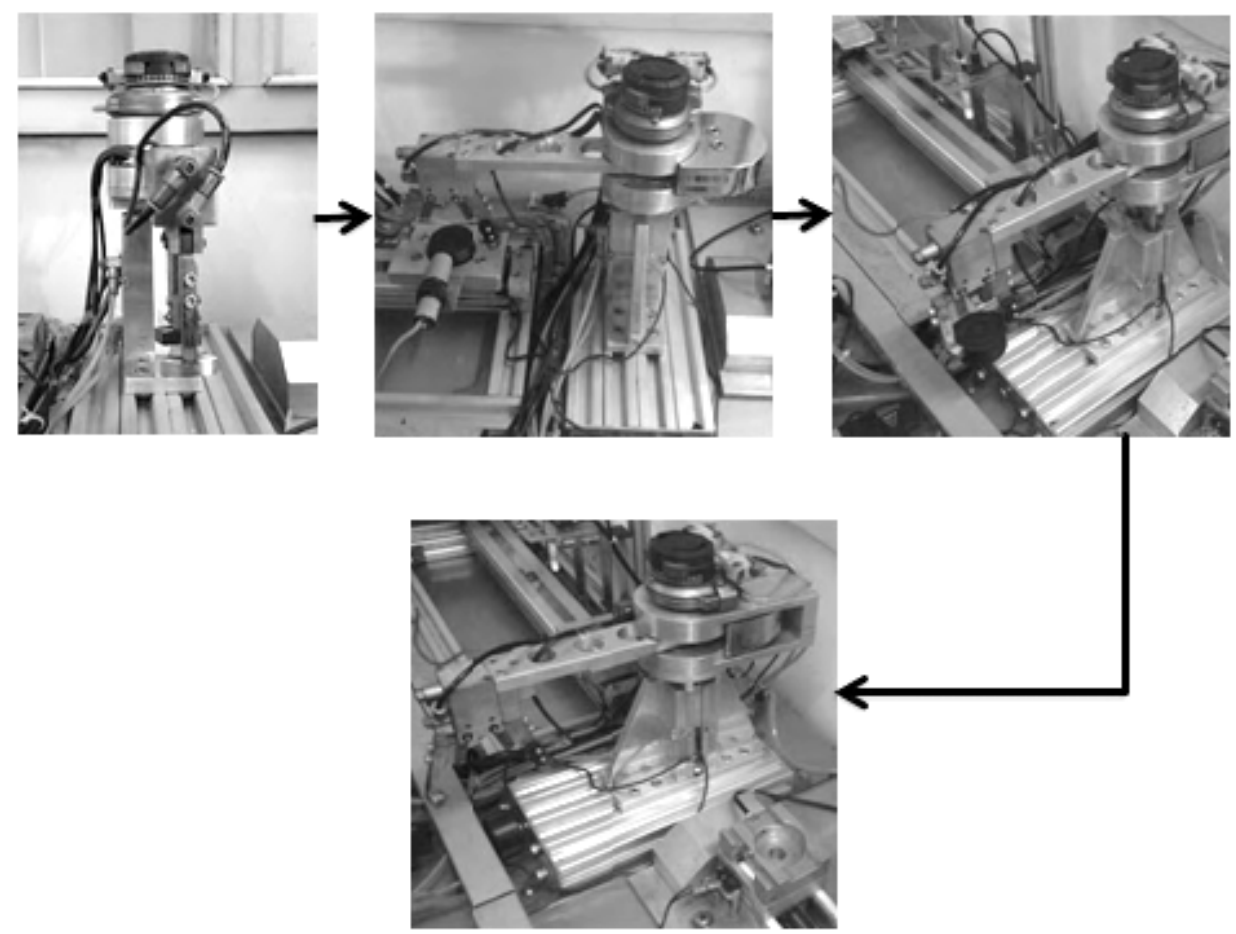

Gambar 5. Rotary handling me-reject 


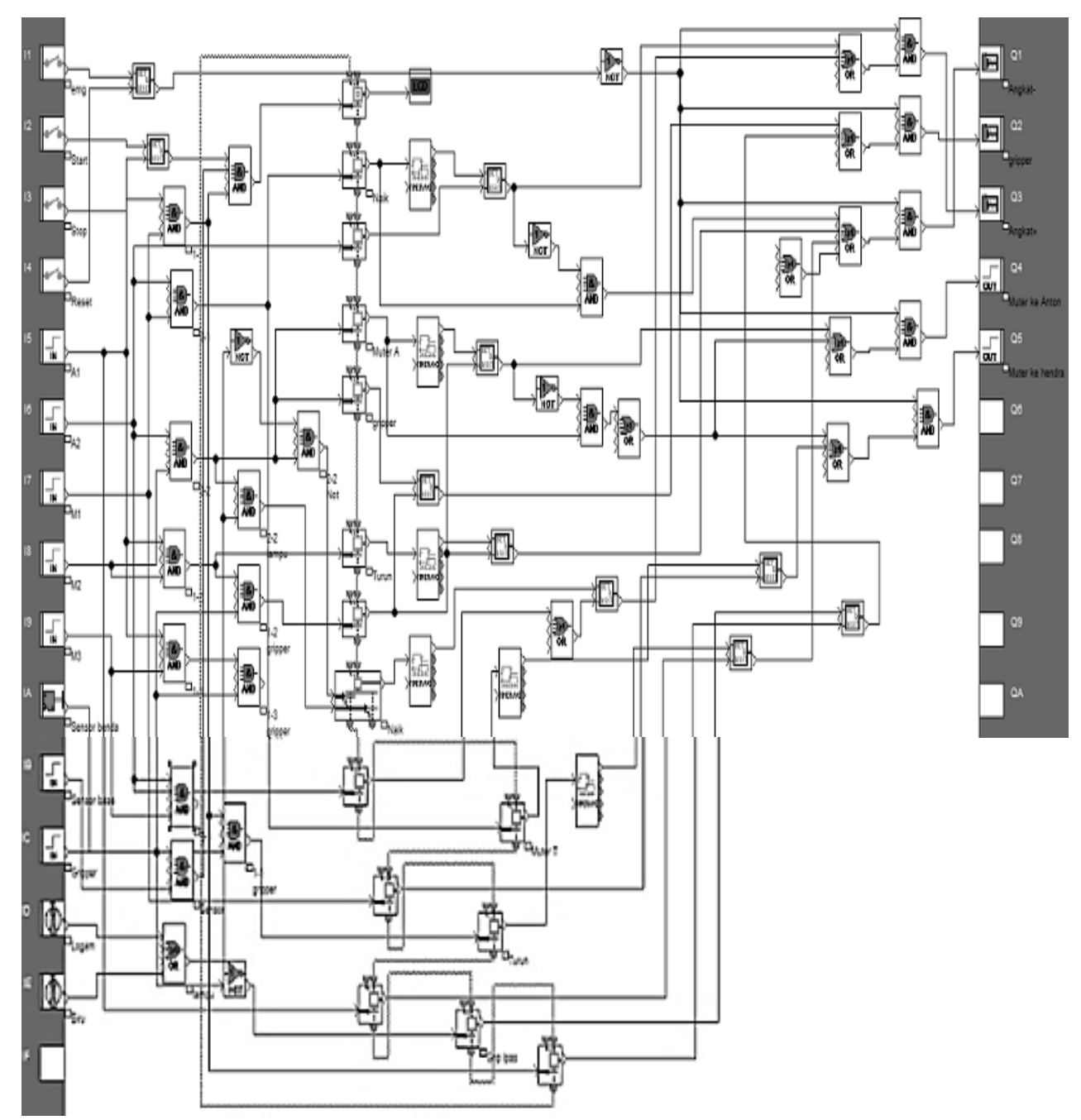

Gambar 6. Program SFC reject benda hitam

Setelah dilakukan pengujian pertama, maka dapat dibuat diagram step proses berdasarkan pengujian yang dilakukan untuk benda berwarna hitam untuk mengetahui sensor-sensor yang terlebih dahulu aktif, actuator bergerak saat syarat suatu sensor yang aktif terpenuhi.

\section{Hasil dari proses pengujian pertama}

Berdasarkan hasil pengujian terhadap benda hitam terdapat kekurangan pada lengan rotari saat berputar kembali ke posisi tengah yaitu:

1. Dikarenakan katup (valve) yang mengatur aliran udara terlalu besar dibuka, akibatnya pada saat lengan bergerak kembali pada posisi tengah untuk membuang benda berwarna hitam, lengan melewati posisi titik tengah mengakibatkan sensor photoelectric (M1) tidak aktif sehingga cylinder lifting yang seharusnya turun, tidak dapat melanjutkan proses karena syarat untuk lifting turun adalah sensor M1 harus aktif.

2. Sensor photoelectric (M1) terlambat mendeteksi, pemberat(bandul) lengan sehingga mengakibatkan tidak tepatnya lengan berhenti pada posisi tengah.

Untuk mengatasi masalah tersebut dilakukan proses secara manual agar lengan dapat kembali keposisi tengah, sehingga cylinder lifting akan turun mengaktifkan sensor A1, dan sensor grip yang aktif karena adanya benda pada gripper, akan memberikan sinyal output agar gripper terbuka, setelah gripper terbuka maka benda hitam yang di jepit akan jatuh. Dalam pengujian yang pertama ini proses dilakukan secara kontinyu. 


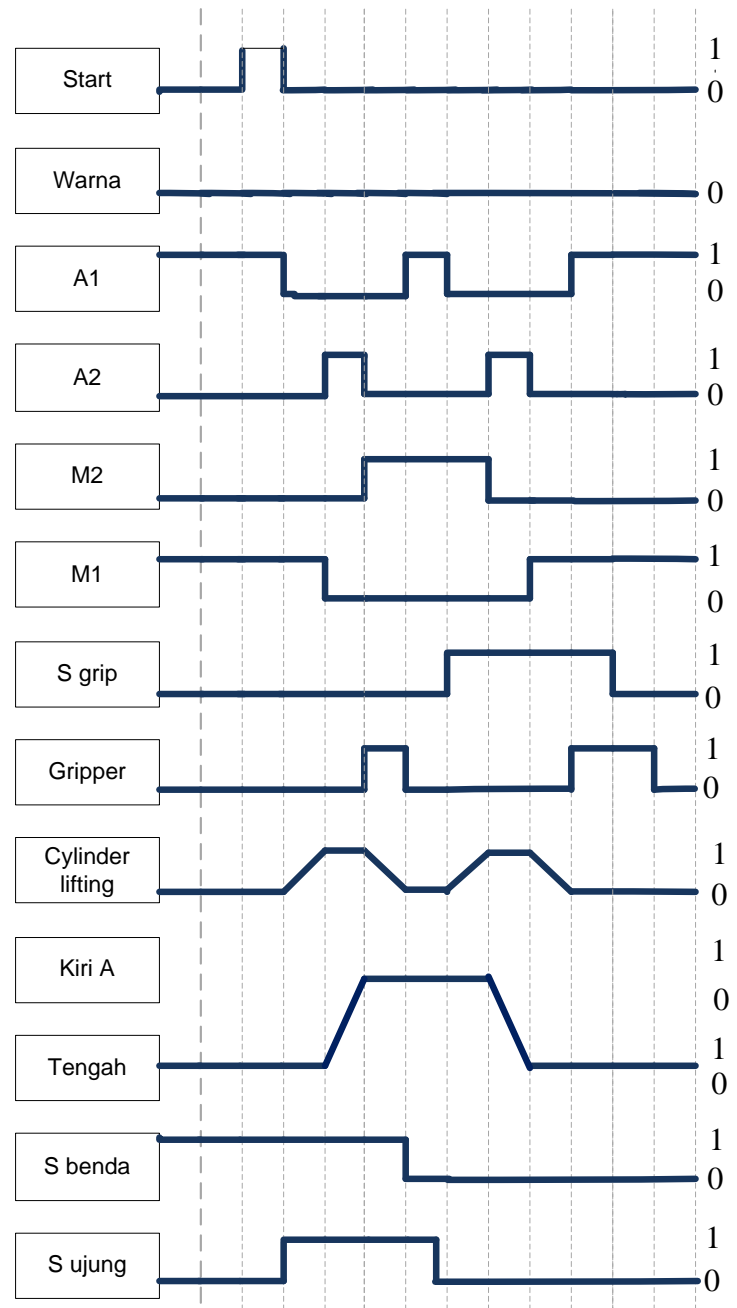

\section{A1: Sensor lifting bagian bawah \\ A2: Sensor lifting bagian atas \\ Sgrip : Sensor gripper \\ M2 : Sensor limit switch modul sorting \\ M1 : Sensor tengah photoelectric rotary}

Kiri A

Motor rotary actuator

Tengah

$\mathrm{S}$ benda : Sensor benda base sorting

S ujung : Sensor ujung proses sorting

Gambar 7. Diagram step pengujian proses benda berwarna hitam

\section{2) Pengujian Benda Non-hitam}

Pada pengujian kedua ini dilakukan terhadap benda berwarna antara logam dan biru untuk mengetahui proses pemindahan benda dan peletakannya ke modul selanjutnya yaitu modul processing.
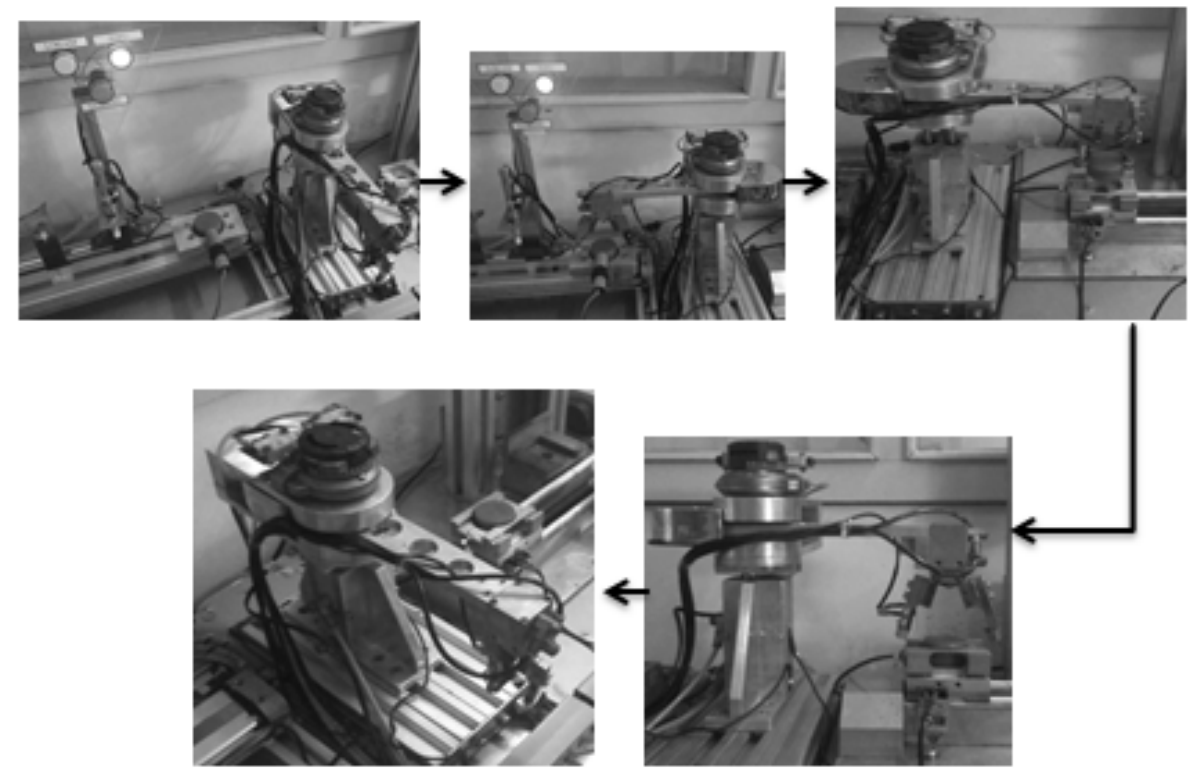

Gambar 8. Rotary handling menempatkan material 


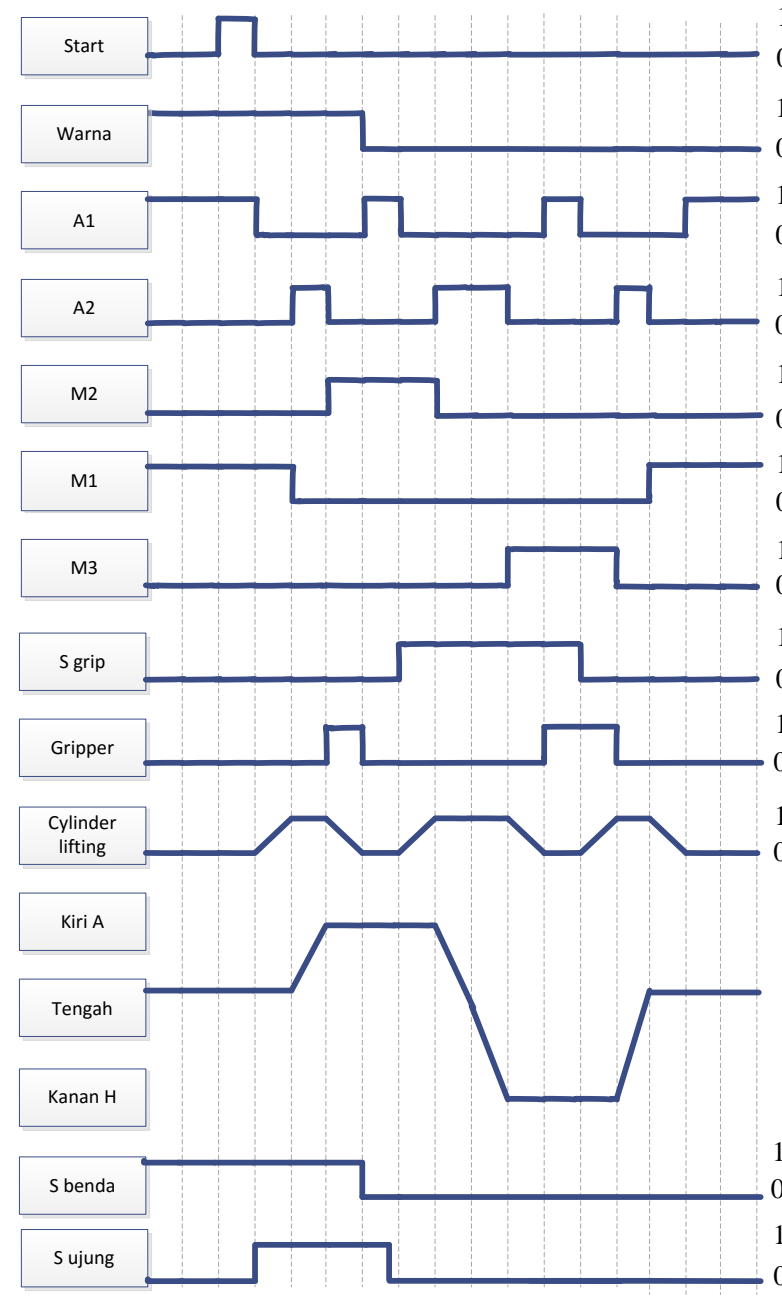

A1: Sensor lifting bagian bawah

A2 : Sensor lifting bagian atas

Sgrip : Sensor gripper

M2 : Sensor limit switch modul sorting

M1 : Sensor tengah photoelectric rotary

M3 : Sensor limit switch modul processing

Kiri A

Tengah Motor rotary actuator

Kanan H

$\mathrm{S}$ benda : Sensor benda base sorting

S ujung : Sensor ujung proses sorting

Gambar 9. Diagram step pengujian proses benda berwarna logam dan biru

\section{Hasil pengujian benda berwarna}

Dari pengujian proses benda berwarna didapat hasil bahwa modul rotary handling dapat bergerak sesuai rencana awal, dari awal pergerakan, pemindahan benda, dan arah putaran lengan untuk meneruskan benda. Akan tetapi, terdapat kekurangan dalam penempatan benda pada modul processing, dimana pembawa benda tidak dapat menerima benda secara tepat. Akibatnya, membuat benda miring dan kemungkinan akan terjatuh bila pembawa benda bergerak menuju proses selanjutnya, oleh karena itu dilakukan perbesaran diameter untuk penempatan benda. Memperbesar diameter ini dilakukan dengan cara melakukan proses pengamplasan sebesar $\pm 1 \mathrm{~mm}$ agar benda yang ditempatkan pada modul processing dapat diletakkan secara tepat pada penempatan benda.

\section{KESIMPULAN DAN SARAN}

\section{Kesimpulan}

Berdasarkan hasil penelitian ini, didapat beberapa kesimpulan dari proses modul rotary handling station antara lain:

1. Waktu kerja yang dibutuhkan satu siklus untuk satu benda kerja:

- Benda hitam

Waktu pengambilan sampai ke posisi pelepasan $=7,8$ detik

- Benda non-hitam

- Waktu pengambilan sampai ke posisi pelepasan = 8,6 detik

Waktu kembali $=4$ detik 
2. Jumlah $I / O$ PLC $=16$ input, 10 output. Yang digunakan untuk modul alat rotary handling station ini adalah input $=15$, dan output $=5$.

3. Modul dapat bekerja dengan baik untuk mensimulasikan proses pemindahan benda dalam skala laboratorium.

4. Program Sequential Function Chart (SFC) dinyatakan berhasil, karena modul alat berjalan sesuai rencana.

\section{Saran}

1. Untuk meminimalkan kerusakan pada alat modul rotary handling station dilakukan perawatan secara rutin.

2. Dalam pembuatan program disarankan program dibuat secara bertahap dalam sistem gerakan suatu modul.

3. Dibutuhkan penggantian double solenoid 5/3 normaly closed pada rotary actuator agar lengan dapat berhenti tepat ditengah.

\section{DAFTAR PUSTAKA}

[1] M. P. Groover, 2001. Automation, Production Systems, and Computer-Integrated Manufacturing, 2nd ed, New Jersey: Prentice-Hall,Inc.

[2] Elsevier, 2004. Introduction to PLC’s, Burlintong: Elsevier Newnes.

[3] H. Khasawneh, 2009. Introduction to PLC and Ladder Logic, Amman: Faculty of Engineering and Technology Universitas Of Jordan.

[4] L. A. Bryan, 1997. Programmable Controllers: Theory and Implementation, Second Edition, Atlanta: An Industrial Text Company Publication. 